\title{
Digestión de lodos residuales de las lagunas de oxidación de Ucubamba, Cuenca
}

\section{Digestion of waste mud in oxidizing lakes at Ucubamba Cuenca}

\author{
Pablo Arévalo Moscoso* y Paulina Lituma Vintimilla
}

Centro de Investigación y Valoración de la Biodiversidad (CIVABI), Universidad Politécnica Salesiana, Cuenca, Ecuador.

*Autor para correspondencia: parevalo@ups.edu.ec.

Manuscrito recibido el 15 de mayo de 2010. Aceptado tras reunión el 3 de julio de 2010

\section{Resumen}

La digestión anaerobia de biosólidos es un proceso que mejora sus características como fertilizante o mejorador de suelos, debido a que existe un grupo de microorganismos bacterianos anaeróbicos presentes en el material fecal que al actuar sobre los desechos orgánicos de origen vegetal y animal, producen una mezcla de gases con alto contenido de metano $\left(\mathrm{CH}_{4}\right)$ llamado biogás, sumamente eficiente si se emplea como combustible. Así, generando residuos con un alto grado de concentración de nutrientes y materia orgánica, ideales como fertilizantes pueden ser aplicados en estado frescos, pues el tratamiento anaerobio elimina patógenos y malos olores. La presenta investigación, muestra cómo se trabajó con un digestor de biosólidos, con un volumen efectivo de tratamiento de 50 litros, con 37,5 de volumen útil bajo condiciones de termofília $\left(53^{\circ} \mathrm{C}\right)$ y mesofilas $\left(23^{\circ} \mathrm{C}\right)$; el cual se alimentó con biosólidos biológicos de la Planta de Tratamiento de Aguas Residuales PTAR de la Cuidad de Cuenca. Éste fue operado a tiempos de retención hidráulica (TRH) de 39 días y el biosólido alimentado se caracteriza por tener un promedio de coliformes fecales de 2,06 E+6, sólidos totales volátiles del 2,8 \% y huevos de helmintos de $2 \mathrm{l} \mathrm{H.H/4g.ST}$. Se obtuvo una reducción de coliformes fecales $(97,2 \mathrm{NMP} / \mathrm{g}$ ST) por debajo de lo establecido en la normativa mexicana (I000.NMP/g ST) con referente a la cuenta de huevos de helmintos, alcanzando valores de 2,4 H.H/4g.ST.

Palabras clave: Huevos de helmintos, digestión anaerobia, mesofílico, termofilica, coliformes fecales, biosólidos.

\section{Abstract}

Anaerobic digestion of waste mud is a process improving the characteristics of mud as a fertilizer and soil improver owing to the existence of a group of anaerobic bacterial microorganisms occurring in fecal matter which act on organic waste of vegetal and animal origin and produce a mixture of gases with large contents of methane $(\mathrm{CH} 4)$ known as biogas. Biogas is particularly efficient if used as a fuel. Thus, waste with high concentration of nutrients and organic matter, ideal as fertilizers, can be used a fresh state because anaerobic treatment kills pathogens and bad smells. This research shows how a digester of biosolids was used with a treatment volume of 50 liters, a useful volume of 37.4 in thermophilic $\left(53^{\circ} \mathrm{C}\right)$ and mesophilic $\left(23^{\circ} \mathrm{C}\right)$ conditions; it was fed with biological biosolids from the Plant of Sewage Treatment PTAR in the city of Cuenca. The plant was operated in hydraulic retention times of 39 days. The fed biosolid is characterized by having an average of fecal coliforms of $2.06 \mathrm{E}+6$, total volatile solids of $2,8 \%$ and helminthes eggs of $21 \mathrm{H} . \mathrm{H} / 4 \mathrm{~g}$.ST.A reduction of fecal coliforms was attained $(97,2 \mathrm{NMP} / \mathrm{g} \mathrm{ST})$, which is under the Mexican norm (I000.NMP/g ST) in relation to the amount of helminthes eggs, with values up to $2.4 \mathrm{H}$.H/4g.ST.

Keywords: helminthes eggs, anaerobic digestion, mesophilic, thermophilic, fecal coliforms, biosolids. 


\section{Introducción}

Debido a la necesidad actual de tratar las aguas residuales generadas en las principales ciudades del Ecuador, se han emprendido varias construcciones de plantas de tratamiento de aguas residuales. Éste tratamiento genera subproductos, como los biosólidos residuales, que representan un gran problema por su volumen de producción y necesidad de estabilización.

En la planta de tratamiento de la ciudad de Cuenca según las batimetrías realizadas por la Empresa de Telecomunicaciones, Alcatarillado y Agua Potable, ETAPA se concluye que el volumen de biosólidos acumulado en las lagunas de la PTAR, Ucubamba a finales del año 2003 fue alrededor de $80000 \mathrm{~m}^{3}$ (Alvarado Martinez, 2005).

Con el fin de disponer adecuadamente de estos biosólidos, deben ser tratados para lograr su estabilización, es decir, reducir la concentración de materia orgánica y el número de patógenos presentes. Los biosólidos estabilizados pueden ser utilizados en la agricultura, en sitios de relleno o ser simplemente incinerados.

Si los biosólidos son procesados para darles apropiadas características bacteriológicas, químicas y físicas, se podría expandir su uso, como posibles fertilizantes. Se tiene que entre los bio-procesos comúnmente utilizados para el tratamiento de biosólidos residuales se encuentra la estabilización anaerobia mesofílica, y el tratamiento anaerobio termofílico, caracterizado por generar poca biomasa y biosólidos estables que tienen características apropiadas para ser utilizados en agricultura.Además, la digestión anaerobia reduce el impacto al ambiente, al prescindir de la adición de reactivos químicos al proceso, requiere muy poca energía externa y es compatible con los criterios de sustentabilidad (Noyola, 1996).

El presente trabajo muestra los resultados obtenidos al tratar Biosólidos residuales secundarios, proveniente de la planta de tratamiento de aguas servidas, de la ciudad de Cuenca utilizando un sistema anaerobio mesofílica y termofílico, como una opción para la producción de biosólidos para uso en la agricultura.

\section{Materiales y Métodos}

Para el desarrollo de la investigación se utilizó un digestor anaerobio de flujo intermitente para el tratamiento de biosólidos con un tiempo de retención de 39 días (Figura I), éste digestor está construido de acero inoxidable de una capacidad de 50 litros de los cuales 37,5 litros es de volumen útil, que se encuentra sellado en la parte superior por una tapa de acero inoxidable con empaque, que dispone de una salida para el biogás con un manómetro para determinar la presión en la cámara.

El mezclado mecánico en el digestor se realiza por medio de un agitador tipo paleta de acero inoxidable soldado a un eje, $y$ accionado por medio de un motor sobre la cubierta de una potencia de $1 / 2$ HP, con un variador de potencia permitiendo regular desde I rpm a $300 \mathrm{rpm}$.

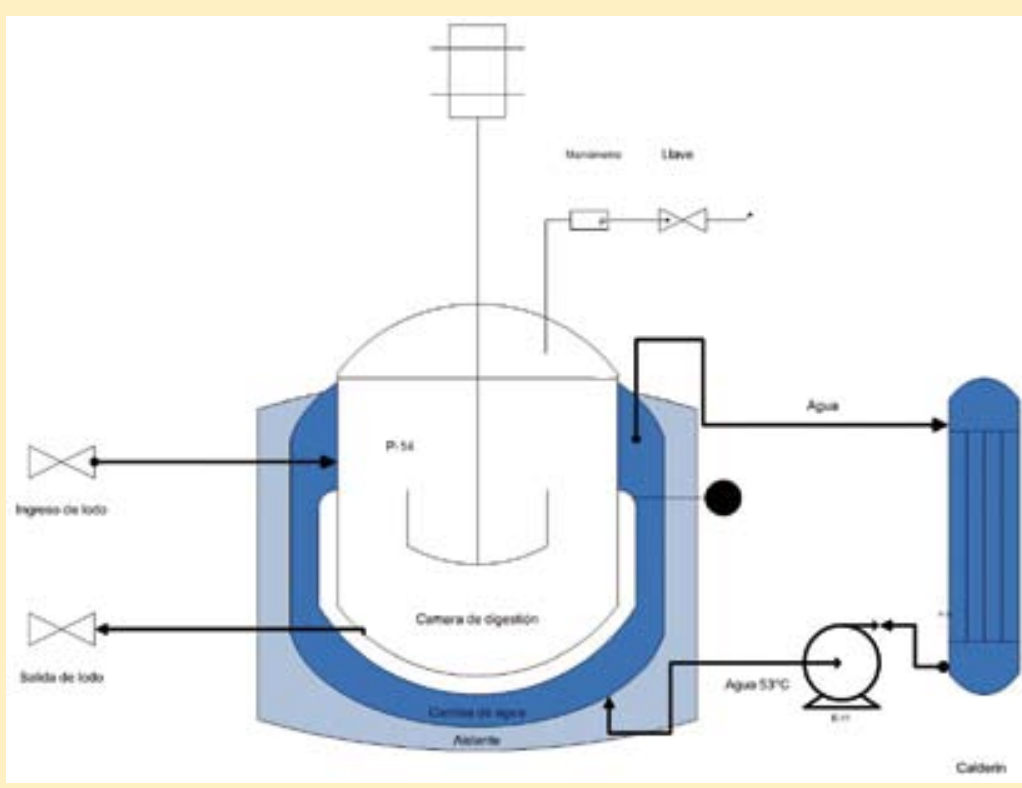

Figura I. Configuración del digestor. Fuente: Pablo Arévalo Moscoso.

Para cubrir los requerimientos caloríficos, el digestor cuenta con una cámara de agua interna. La cámara de agua está constituida con una línea de recirculación a través de un sistema intercambiador de calor para alcanzar la temperatura requerida con una resolución de $\pm 3{ }^{\circ} \mathrm{C}$. Esta cámara se encuentra cubierta por una pared de aislamiento térmico para disminuir pérdidas de calor y con un punto de monitoreo de temperatura en el digestor. 


\section{I Criterios de operación y análisis}

Para la alimentación del biodigestor, se procedió a tomar cuatro muestras de biosólidos de las lagunas de oxidación de la ciudad de Cuenca en una cantidad de 10 galones cada 45 días; posteriormente se homogenizaron y aclimatizaron por una hora y a continuación se tomó una muestra de $500 \mathrm{cc}$ antes de depositar en el digestor. Cabe indicar que de las cuatro muestras dos fueron tratadas con una temperatura de $23^{\circ} \mathrm{C}$ y las otras dos a $53^{\circ} \mathrm{C}$. La temperatura en el digestor se incrementa $5^{\circ} \mathrm{C}$ a intervalos de 2 horas llegando a alcanzar la temperatura ideal de trabajo.

En la primera muestra se caracterizaron e identificaron los microorganismos presentes en el biosólido determinando la presencia de hongos y bacterias. En el caso de los hongos se encontró: Mucor hiemalis, Absidia sp, Mucor varians, Emericellopsis.sp, Circinella simplex, Mucor circinelloides, Mortierlla.sp, Popularia. sp, Paecilomyces sp, Zygorhynchus sp, Hansfordia $s p$, Penicillium chrysogenum, Geniculosporium sp, Absidia $s p$, Mucor varians. Mientras que entre las bacterias se contaron: Coccubacillus sp, Streptobacillus sp, Staphylococcus sp, Streptococcus sp, Bacillus sphaericus, Bacillus sp, Bacillus subtilis, Bacillus vulgaris, Pseudomonas sp, Salmonella typhosa.

En todas las muestras se procedió a determinar coliformes fecales, coliformes totales, sólidos totales, sólidos volátiles, potencial de hidrógeno $\mathrm{pH}$, huevos de helmintos y cromo total. utilizando laboratorios externos, en donde se realizaron los exámenes de las muestras.

Para controlar el proceso de digestión se determinaron: coliformes totales, potencial de hidrogeno $\mathrm{pH}$, temperatura, densidad, sólidos volátiles, sólidos totales y presión del digestor todos los días. En intervalos de 3 días se procedió a determinar, levaduras y cromo +6 , éstos exámenes se realizaron en los laboratorios del Centro de Investigación y Valoración de la Biodiversidad de la Universidad Politécnica Salesiana, sede Cuenca.

Luego del proceso de digestión se procedió a separar por gravedad en el mismo digestor a temperatura ambiente, sin agitación y retirada la tapa superior del digestor por un tiempo de 2 días obteniendo una parte líquida (lixiviado) y el biosólido de los cuales se toma una muestra de $200 \mathrm{cc}$. De estas dos partes se realizaron los análisis en laboratorios externos re- conocidos en la zona los siguientes parámetros: coliformes fecales, coliformes totales, sólidos totales, sólidos suspendidos volátiles, potencial de hidrógeno $\mathrm{pH}$, huevos de helmintos y cromo total para el biosólido; y coliformes totales y coliformes termo temporales para lixiviado.

\subsection{Condiciones de operación.}

Para el desarrollo de la investigación se determinaron las características del biosólido (Tabla I) a trabajar sometido al proceso de digestión a temperatura de 23 ${ }^{\circ} \mathrm{C}$ para la muestra uno y tres y de $53^{\circ} \mathrm{C}$ para la muestra dos y cuatro. La agitaciones se realizaron cada 12 horas por un intervalo de I hora a $50 \mathrm{rpm}$.

Tabla I. Características de los biosólidos.

\begin{tabular}{|c|c|c|c|c|c|}
\hline PARÁMETROS & unidad & MI & M2 & MII & MII \\
\hline $\begin{array}{l}\text { Coliformes } \\
\text { fecales }\end{array}$ & $\mathrm{NMP} / \mathrm{g}$ & $3,80 E+6$ & $3,60 E+6$ & $3,70 E+6$ & $3,75 E+6$ \\
\hline $\begin{array}{l}\text { Coliformes } \\
\text { Totales }\end{array}$ & $\mathrm{NMP} / \mathrm{g}$ & $5,00 \mathrm{E}+6$ & $5,25 E+6$ & $4,95 \mathrm{E}+6$ & $5,12 \mathrm{E}+6$ \\
\hline $\begin{array}{l}\text { Sólidos } \\
\text { totales }\end{array}$ & $\%$ & 13,00 & 13,2 & 12,9 & 13,1 \\
\hline $\begin{array}{l}\text { Sólidos } \\
\text { volátiles }\end{array}$ & $\%$ & 3,00 & 2,95 & 3,10 & 2,90 \\
\hline $\mathrm{Ph}$ & & 6,95 & 6,90 & 7,01 & 6,80 \\
\hline $\begin{array}{l}\text { Huevos } \\
\text { Helmintos }\end{array}$ & $\mathrm{HH} / \mathrm{g}$ & 73,00 & 76,00 & 70,00 & 71,00 \\
\hline Cromo & $\mathrm{mg} / \mathrm{Kg}$ & 330,00 & 360,00 & 401,00 & 320,00 \\
\hline $\begin{array}{l}\text { Temperatura } \\
\text { de trabajo }\end{array}$ & ${ }^{\circ} \mathrm{C}$ & 23 & 53 & 23 & 53 \\
\hline
\end{tabular}

Según los estudios realizados por ETAPA (Alvarado Martínez, 2005), las características de los lodos o biosólidos de acuerdo a la norma NOM-004-SEMARNAT-2002, en función de su contenido de metales tiene la característica excelente; mientras que respecto al indicador bacteriológico y parásitos no cumple la norma. En referencia a la regulación 503 de la US EPA en relación del contenido de metales es de Tipo A, pero en referencia a los patógenos es de tipo B, por lo que para su utilización en el suelo en actividades agrícolas solo se aplicara uno de los tipos de tratamiento mencionados en la regulación 503 de la US EPA (Promas, 2005) como la digestión anaerobia. 


\section{Resultados}

El pH determinado del biosólido en la digestión mesofílica alcanza un valor promedio de 7,73 mientras que en la digestión termófila alcanza el valor de 7,87. (Figura 2).

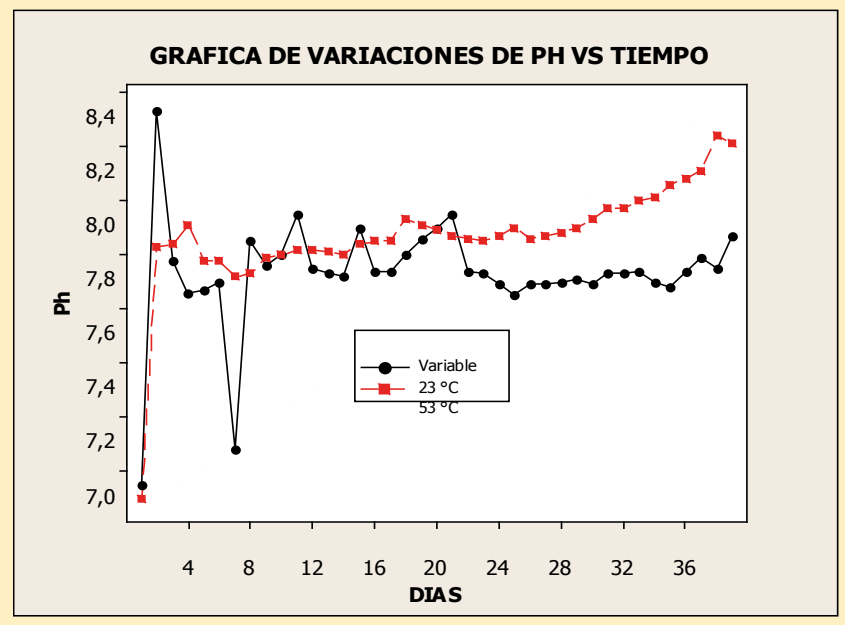

Figura 2. $\mathrm{pH}$ vs tiempo para las muestras sometidas a dos temperaturas diferentes. Fuente: Pablo Arévalo Moscoso

Los coliformes totales del lixiviado alcanzaron un valor promedio de $1245264 \mathrm{UCF} / \mathrm{ml}$ con un mínimo de $160 \mathrm{UCF} / \mathrm{ml}$ en la digestión mesofílica y la termofilica un promedio de $536410 \mathrm{UCF} / \mathrm{ml}$ alcanzando el minimo de $200 \mathrm{UCF} / \mathrm{ml}$. (Figura 3).

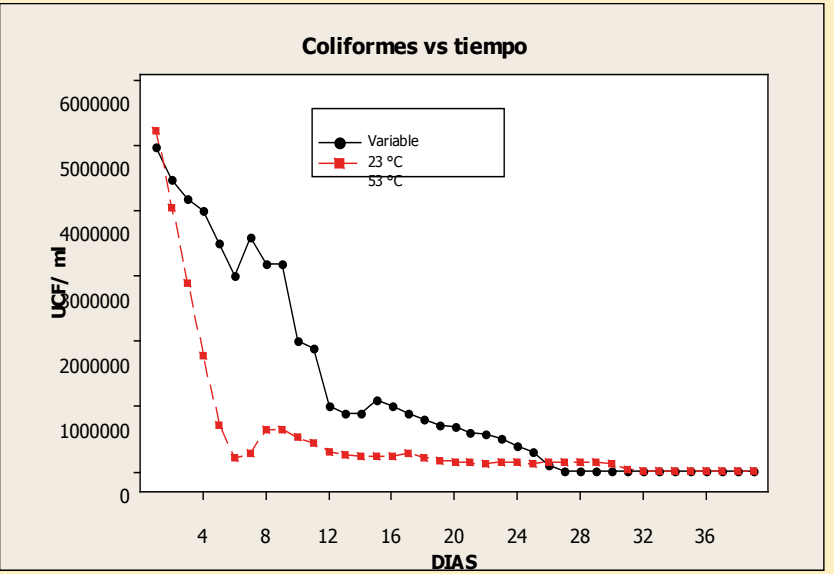

Figura 3. Evolución de los coliformes en el tiempo en muestras sometidas a dos temperaturas. Fuente: Pablo Arévalo Moscoso.

Con respecto al volumen producido de biogás tenemos un máximo de 1 13,97 litros en la digestión mesofílica y 247,83 litros en la termofílica con una composición del $67 \%$ de Metano.
En relación con los sólidos totales del Biosólido tenemos un promedio de $28,64 \%$ para la digestión mesofilica y para la termófila de $24,71 \%$ siendo el valor más alto de $39,34 \%$ para la mesofílica y para la termofílico de $34,54 \%$ (Figura 4).

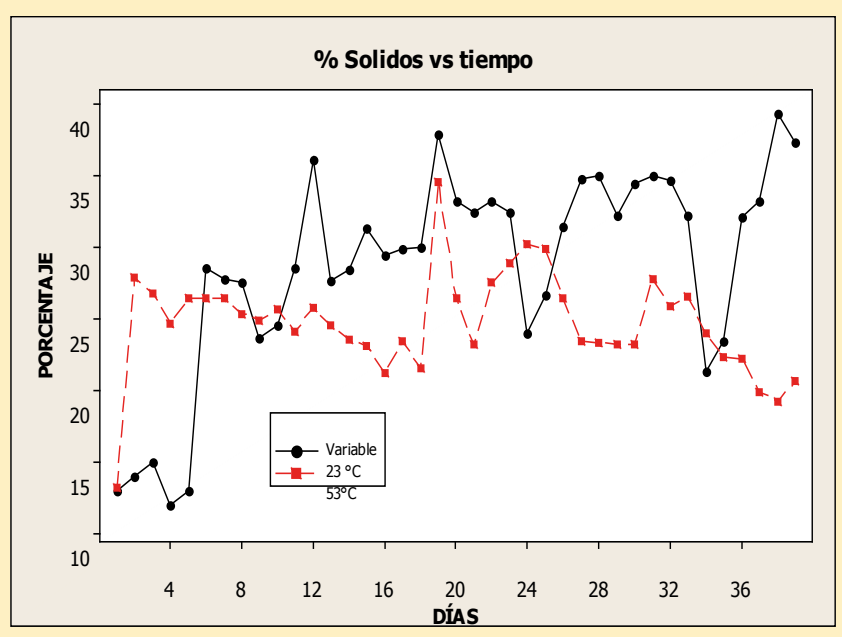

Figura 4. Porcentaje de sólidos totales vs. tiempo. Fuente: Pablo Arévalo Moscoso.

Mientras que para el porcentaje sólidos volátiles tenemos un promedio de $3,81 \%$ en la digestión mesofílica y de $2,06 \%$ en la digestión termofílica alcanza un máximo de 11,79 y 3,65 respectivamente. La densidad del Biosólido se encuentra en una media de I,06 para la digestión mesofílica y I,05 para la termofílica

Al final de los 39 días de digestión termofílica las características del biosólido alcanzaron valores promedios de 97,2 NMP/g coliformes totales, 2,4 huevos de helmintos/g mientras el lixiviado presenta valores de coliformes de $240 \mathrm{NMP} / 100 \mathrm{ml}$. La digestión mesofílica se caracterizó por tener valores de 92 $\mathrm{NMP/g}$ coliformes totales, I,9 huevos de helmintos/ $\mathrm{g}$ mientras el lixiviado presenta valores de coliformes de $260 \mathrm{NMP} / 100 \mathrm{ml}$.

Estos resultados en relación a la norma mexicana, indican que el biosólido se clasificaría en la categoría excelente y de tipo B, por lo que el lodo puede ser aprovechado en la zona urbana sin contacto público directo, para usos forestales, mejoramiento de suelos y usos agrícolas. El lixiviado cumple con la normativa nacional para uso de riego con respecto a coliformes totales alcanzando un valor menor con el establecido por la norma que es de 1000 NMP / $100 \mathrm{ml}$. 


\section{Discusión}

En comparación al funcionamiento del proceso de digestión mesofílica y termofílica se determinó ya que el proceso termofílico produce más volumen de biogás que el mesofilico estableciéndose una semejanza en el día 25 en que el $\mathrm{pH}$ pierde su estabilidad y disminuye la producción del biogás. El volumen de biogás obtenido con una concentración de metano del $67 \%$ es muy bajo de acuerdo a parámetros establecidos para desechos municipales que tienen un índice de $0,2 \mathrm{~m}^{3} \mathrm{CH}_{4}$ I kg SV (WWF, 2003) mientras que en nuestro trabajo obtenemos valores para el proceso termofílico de $0,15 \mathrm{~m}^{3} \mathrm{CH}_{4} / \mathrm{kg}$ SV y el mesofílico de $0,04 \mathrm{~m}^{3} \mathrm{CH}_{4} /$ $\mathrm{kg} \mathrm{SV}$ muy por debajo de ese valor. (Figura 5).

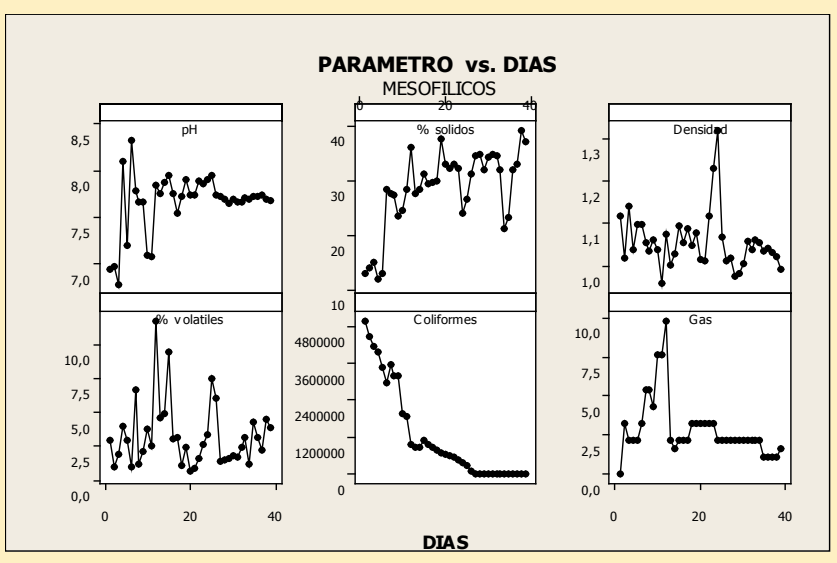

Figura 5. Variación del parámetro en el número de días. Fuente: Pablo Arévalo Moscoso.

Se verifica la relación existente entre coliformes totales-días obteniendo un valor de coeficiente de correlación de $-0,89$ para la mesofilica y un valor de $-0,61$ para la termofilica. Se confirma que el $\mathrm{pH}$ en la digestión termofilica es más estable, ya que su varianza es de 0,049 mientras que la digestión mesofilica tiene un valor de 0,100

Debemos indicar que el porcentaje de sólidos volátiles en relación a sólidos totales tienen un valor promedio de $20 \%$ menor a los estándares de 45-60 \% (Crites \& Tchobanoglous, 2000), y la relación de Sólidos Volátiles / Sólidos Totales es de 12,50, muy en relación de otras fuentes, que dan valores alrededor del 70 \% en promedio (WWF, 2003). Finalmente podemos indicar que los resultados de las características del biosólido no cumplen con lo establecido para la categoría $A$ ingresando a la categoría $B$.

\section{Conclusiones}

En el proceso termofílico mantuvo un mejor y adecuado nivel de $\mathrm{pH}$. Además, los resultados muestran que la digestión mesofílica alcanza mejores resultados para obtener un biosólido de clase $B$ que los procesos termofílico. De esta manera se concluye que para una mayor producción de biogás el proceso termofílico es el mejor proceso que el mesofílico.

La digestión anaerobia con una fase mesofílico y otra termofílico, puede ser una opción adecuada para obtener biosólidos de tipo $\mathrm{A}$, al combinar las ventajas individuales y evitar las desventajas de cada una.

\section{Agradecimiento}

Los autores agradecen el financiamiento de esta línea de investigación a la Universidad Politécnica Salesiana del Ecuador, como a la Dirección de Gestión Ambiental de ETAPA por permitir la utilización los lodos de la planta de tratamiento de aguas residuales de Ucubamba.

\section{Referencias}

Alvarado Martinez, A. O. 2005. Drying of Stabilisation Pond Sludge and Its. Cuenca: Tesis para obtar el grado de Magister en el Instituto de la educación del Agua UNESCO.

Crites, r., \& Tchobanoglous, G. 2000. Tratamiento de Aguas Residuales en Pequeñas Poblaciones . Santafé de Bogota: Colombia.

Federación, D. O. 2002. Lodos y Biosólidos. Especificaciones y Limites máximos permisibles de contaminantes para su aprovechamiento y disposición final. México.

Noyola, A. 1996. Anaerobic Technology as a Tool for the Sustainable Environment; the contex of Mexico. Mexico: UNAM.

Promas. 2005. Informe final de los trabajo comtemplados en el convenio ETAPA y PROMAS. Cuenca.

WWF, N. F. 2003. Energías renovables: conceptos y aplicaciones. Quito: La Unión. 